\title{
STABILITY ENHANCEMENT OF PROTON PUMP INHIBITOR IN STOMACH: FORMULATION AND IN VITRO EVALUATION OF STABILIZED PROTON PUMP INHIBITOR
}

\author{
ARAVIND PM, MAHALAXMI RATHNANAND*, MADHU KUMAR C \\ Department of Pharmaceutics, Manipal College of Pharmaceutical Sciences, Manipal University, Manipal, Karnataka, India. \\ Email: mlrcops2002@yahoo.co.in
}

Received: 19 January 2017, Revised and Accepted: 07 February 2017

\section{ABSTRACT}

Objective: The aim of the present study was to prepare a pantoprazole rosin complex tablet which would stabilize the drug in the mild acidic condition (pH 5) of the stomach during the fed state.

Methods: The method of slow solvent evaporation and antisolvent was used for the preparation of pantoprazole rosin complex.

Results: The prepared pantoprazole rosin complex exhibited decreased solubility than that of pure drug. Fourier transform infrared spectroscopy and differential scanning calorimetry studies confirmed the formation of a complex between the pantoprazole sodium and rosin through weak ionic bonds. The in vitro release studies of the pantoprazole rosin complex showed more than $80 \%$ release at the end of 90 minutes. Tablets were formulated using direct compression method and the prepared tablets were evaluated in vitro. The tablets were found to be within official limits with respect to hardness, weight variation, drug content, friability, etc.

Conclusion: The tablet formulated with croscarmellose sodium as superdisintegrant showed $97 \%$ drug release within 60 minutes. The optimized tablets were found to be stable in accelerated study conditions for 1 month with respect to physical characteristics and drug content. If this process can be scaled up to manufacturing level, this technique has the potential to develop into an invaluable technology in future.

Keywords: Pantoprazole rosin complex, Proton pump inhibitor, Croscarmellose sodium.

(C) 2017 The Authors. Published by Innovare Academic Sciences Pvt Ltd. This is an open access article under the CC BY license (http://creativecommons. org/licenses/by/4. 0/) DOI: http://dx.doi.org/10.22159/ajpcr.2017.v10i5.17179

\section{INTRODUCTION}

Proton pump inhibitors are majorly used in the treatment of peptic ulcer disease, gastroesophageal reflux disease in adults and children, risk reduction of non-steroidal anti-inflammatory drugs-associated gastric ulcer, Helicobacter pylori eradication, and control of pathological hypersecretory conditions associated with Zollinger-Ellison syndrome [1], stress gastritis prophylaxis. Proton pump inhibits gastric secretion by binding with the $\mathrm{H}+/ \mathrm{K}+$ ATPase proton pump present embedded at the apical membrane of the parietal cell.

The proton pump inhibitors are substituted benzimidazoles that are acid labile which shows poor stability at low $\mathrm{pH}$. The stability of proton pump inhibitors decreases as $\mathrm{pH}$ decreases. They are stable at neutral and mildly acidic condition. At present, enteric coating is done to such acid labile drugs to prevent its degradation in the stomach. At lower $\mathrm{pH}$ levels, they become protonated and accumulate in the strongly acidic environment such as those found in the canaliculi of gastric cells. Here, these get converted to the sulfenic acid which is in equilibrium with the cyclic sulfonamide which binds to cysteine residues on the subunits of the proton pump, thereby inhibiting the secretion of gastric acid. The acid-catalyzed conversion of the proton pump inhibitors to activate sulfenamide determines the rate of inactivation of the $\mathrm{H}+/ \mathrm{K}+$ ATPase enzyme. The acid secretion is blocked until there is de novo biosynthesis of a new enzyme, which usually occurs within about $96 \mathrm{hrs}$. Thus, they were much superior compared to $\mathrm{H}_{2}$ receptor antagonist and antacid in providing higher intragastric $\mathrm{pH}$ control [2].

Among the available proton pump inhibitors, pantoprazole has stood out due to the following reasons: Pantoprazole has lower $\mathrm{pH}$ activation and demonstrates greater stability than other proton pump inhibitors in mildly acidic conditions. Activation at lower $\mathrm{pH}$ makes pantoprazole more gastro selective. It was proved that once daily dose of $40 \mathrm{mg}$ in the morning was effective for treating both grade 2 and more severe grades of erosive esophagitis (grades 3 or 4) after both 4 and 8 weeks of treatment. Pantoprazole shows greater efficiency than other proton pump inhibitor and $\mathrm{H}_{2}$ receptor antagonist. Pantoprazole also exhibits safety and tolerability in many patients [3].

Pantoprazole sodium sesquihydrate (PSS) is chemically known as sodium 5-(difluoromethoxy) - 2 - [[(3, 4-dimethoxy-2-pyridinyl) methyl] sulfinyl]-1H-benzimidazole sesquihydrate [4].

\section{MATERIALS AND METHODS}

Materials

PSS was obtained from RA Chem Pharma Ltd, Hyderabad. All other materials used were of pharmacopoeial grade and were produced from commercial sources.

\section{Methods}

\section{Formulation development}

Preparation of pantoprazole rosin complex

The method of slow solvent evaporation and antisolvent was used for the preparation of pantoprazole rosin complex. Methanol and ethanol were considered for the study since both rosin and drug were soluble in alcohol. Both water and n-hexane were tested as antisolvent. It was found that water is a suitable antisolvent and formed pantoprazole rosin complex. Thus, water was considered for further studies.

Specific amount of pantoprazole sodium and rosin was dissolved in $10 \mathrm{ml}$ of ethanol using magnetic stirrer at $400 \mathrm{rpm}$ taken in a $50 \mathrm{ml}$ beaker. The solvent was allowed to be evaporated until it formed a viscous supersaturated solution. The specific amount of water was added as antisolvent to this while raising the rpm of the magnetic stirrer to $900 \mathrm{rpm}$. The solution was allowed to mix for 3 minutes. 
Pantoprazole rosin complex precipitated out as a white precipitate. The solution was filtered using Whatman filter paper and allowed to dry in open air [5].

Optimization of pantoprazole rosin complex

The ratio of drug: Rosin is varied to determine the optimized pantoprazole rosin complex formation as shown in Table 1 . In the case of pantoprazole sodium, rosin 1:2, an attempt was made to stabilize or overcome the gummy nature of rosin gum using magnesium stearate as stabilizer and lubricant [6].

\section{Determination of practical yield}

The pantoprazole rosin complex obtained after the addition of antisolvent was allowed to mix for 3 minutes. Then, it was filtered through $41 \mu \mathrm{m}$ Whatman filter paper and allowed to dry in open. The practical yield was measured after overnight drying for $12 \mathrm{hrs}$

\section{Determination of drug content}

A dose of $10 \mathrm{mg}$ of pantoprazole rosin complex was weighed accurately and transferred to $100 \mathrm{ml}$ volumetric flask containing $75 \mathrm{ml}$ of distilled water, shaken for few minutes and the volume was made up to mark with distilled water. It was sonicated for 8 minutes and the solution was passed through Whatman filter paper $41 \mu \mathrm{m}$. The filtrate was checked for absorbance at $289 \mathrm{~nm}$ [7].

Characterization of pantoprazole rosin complex by differential scanning calorimetry (DSC) and Fourier transform infrared spectroscopy (FTIR)

DSC

DSC was performed using DSC-60, Shimadzu, Japan. The samples were scanned at a rate of $5^{\circ} \mathrm{C} /$ minutes from $25^{\circ} \mathrm{C}$ to $250^{\circ} \mathrm{C}$

\section{Infrared spectroscopy}

Infrared spectroscopy was conducted using a Shimadzu FTIR 8300 spectrophotometer, and the spectrum was recorded in the region of $4000-400 / \mathrm{cm}$.

\section{Physical stability testing of pantoprazole rosin complex in} different $\mathrm{pH}$

Quantity equivalent to $10 \mathrm{mg}$ of pure pantoprazole sodium was accurately weighed and transferred to $10 \mathrm{ml}$ test tubes. The stability of pantoprazole rosin complex was performed at different $\mathrm{pH}$ in $0.1 \mathrm{M}$ hydrochloric acid (pH 1.2), phosphate buffer $\mathrm{pH}$ 5, pH 6.8, and pH 7.4. The result was compared with pure pantoprazole sodium in the same solvent. Studies were observed for 90 minutes. The observation was noted at time intervals $0^{\text {th }}, 5^{\text {th }}, 10^{\text {th }}, 15^{\text {th }}, 30^{\text {th }}, 45^{\text {th }}, 60^{\text {th }}$, and $90^{\text {th }}$ minutes [8].

\section{Formulation of the tablet using pantoprazole rosin complex}

Pantoprazole sodium tablet was prepared using 10 station automatic tablet compression machine (Rimek Mini Press 1). The excipients were selected based on direct compressibility of pantoprazole sodium [9]. Formula for pantoprazole rosin complex tablet is shown in Table 2.

Procedure of preparation of tablets by direct compression The ingredients except for drug rosin complex were mixed in the descending order of weights, followed by the addition of drug rosin complex. Then blending was done for 10 minutes. And then, the blend was transferred through sieve \#44. After sieving, blend required for each tablet was weighed individually and punching of tablets was performed using the Manual Tablet Compaction Machine (hydraulic pump mechanism).

Table 1: Optimization of pantoprazole rosin complex

\begin{tabular}{ll}
\hline Trials & Drug: Rosin ratio \\
\hline Trial 1 & $1: 0.5$ \\
Trial 2 & $1: 1$ \\
Trial 3 & $1: 2$ \\
\hline
\end{tabular}

Analysis of pre-compression blend and tablets

Pre-compression blends were tested for angle of repose, compressibility index, and Hausner ratio. Compressed tablets were evaluated for weight variation, friability, and hardness as per the standard procedure.

\section{Disintegration test}

The time required for the tablet to disintegrate and pass through $2.0 \pm 0.2 \mathrm{~mm}$ mesh of the disintegration apparatus was noted as per the systematic procedure [10].

\section{Assay}

Five tablets were randomly selected and powdered. A volume of $10 \mathrm{mg}$ of the powder was weighed and transferred to a $100 \mathrm{ml}$ volumetric flask and dissolved in $75 \mathrm{ml}$ of distilled water. The solution was then sonicated in a bath sonicator for 8 minutes. The solution was then made up to the mark with distilled water. Then, the solution was filtered through Whatman filter paper $(41 \mu \mathrm{m})$. The filtrate was analyzed by UV spectrophotometry at $289 \mathrm{~nm}$ against water as blank.

\section{In vitro release studies: Dissolution testing}

The in vitro drug release studies for the prepared formulation were conducted for $2 \mathrm{hrs}$ using an electrolab model dissolution tester USP type - I apparatus (rotating paddle), set at $100 \mathrm{rpm}$ and a temperature of $37 \pm 0.5^{\circ} \mathrm{C}$ with $900 \mathrm{ml}$ of the pH5 phosphate buffer as medium. At specified intervals, $2 \mathrm{~mL}$ samples were withdrawn from the dissolution medium and replaced with fresh medium to keep the volume constant. The absorbance of the sample solution was analyzed at $289 \mathrm{~nm}$ for the presence of the model drug, using a UV-visible spectrophotometer [11].

Selection of dissolution media was based on the stability testing performed for both pantoprazole and pantoprazole rosin complex at different $\mathrm{pH}$. The $\mathrm{pH} 5$ dissolution media was selected considering the fact that it represents the stomach condition during fed state and dissolution medium volume was set at $900 \mathrm{ml}$ to suit the fed stomach condition

\section{Stability studies on optimized tablets}

Stability studies were performed on optimized tablets, according to the guidelines by ICH at accelerated study conditions $\left(30 \pm 2^{\circ} \mathrm{C}\right.$ and $65 \pm 5 \% \mathrm{RH})$. The study was conducted for the duration of 1 month. Tablets were wrapped with aluminum foil (primary packing) and were placed inside a plastic container. The samples were taken out on the $30^{\text {th }}$ day and were evaluated for release profiles [12]

\section{RESULTS AND DISCUSSION}

\section{Optimization of pantoprazole rosin complex}

It was observed that best result was obtained when drug-rosin ratio was $1: 1$. When the drug-rosin ratio was increased to $1: 2$, the complexation reaction was incomplete due to overall greater cohesive and gummy nature of the rosin gum. Reduction of the drug-rosin ratio to $1: 0.5$, the viscous supersaturated state was not observed as seen with 1:1 drug-rosin ratio

\section{Determination of percentage yield}

The practical yield obtained was better with drug: rosin ratio 1:1 than other ratios.

\section{Determination of drug content}

When the solution was sonicated, it was found that some particles remained undissolved and were separated by filtration through Whatman filter paper $41 \mu \mathrm{m}$. It was assumed that this undissolved particle was the rosin component of pantoprazole rosin complex. Thus, when the filtrate was scanned from $400 \mathrm{~nm}$ to $200 \mathrm{~nm}$, the spectra of filtrate and the pure pantoprazole sodium were found to be same. Thus, assuming the concept that the bond between pantoprazole and rosin component was temporary and it is sufficient to pass through the stomach membrane and get absorbed due to the lipophilic nature of the rosin gum. It was found that $13 \mathrm{mg}$ of pantoprazole rosin complex was equivalent to $10 \mathrm{mg}$ of pantoprazole sodium. 
Table 2: Formulae for pantoprazole rosin complex tablets

\begin{tabular}{|c|c|c|c|c|c|c|c|c|c|c|}
\hline Ingredients & F1 & F2 & F3 & F4 & F5 & F6 & F7 & F8 & F9 & F10 \\
\hline Pantoprazole rosin complex (mg) & 26 & 26 & 26 & 26 & 26 & 26 & 26 & 26 & 26 & 26 \\
\hline Microcrystalline cellulose (mg) & 154 & - & - & - & - & - & - & - & - & - \\
\hline Ethyl cellulose (mg) & - & 154 & - & - & - & - & - & - & - & - \\
\hline Directly compressible lactose (mg) & - & - & 154 & - & 77 & - & - & - & - & - \\
\hline Avicel 112 (mg) & - & - & - & 154 & 77 & 154 & 154 & 159 & 159 & 157 \\
\hline Sodium starch glycolate (mg) & 10 & 10 & 10 & 10 & 10 & - & - & - & - & - \\
\hline Crospovidone (mg) & - & - & - & - & - & 10 & - & 5 & - & 7 \\
\hline Poly vinyl pyrrolidine $40 \mathrm{~K}(\mathrm{mg})$ & 5 & 5 & 5 & 5 & 5 & 5 & 5 & 5 & 5 & 5 \\
\hline Magnesium stearate (mg) & 2 & 2 & 2 & 2 & 2 & 2 & 2 & 2 & 2 & 2 \\
\hline Talc (mg) & 3 & 3 & 3 & 3 & 3 & 3 & 3 & 3 & 3 & 3 \\
\hline Total (mg) & 200 & 200 & 200 & 200 & 200 & 200 & 200 & 200 & 200 & 200 \\
\hline
\end{tabular}

\section{Characterization of pantoprazole rosin complex with DSC and FTIR}

DSC

Shift in the peak from $155.14^{\circ} \mathrm{C}$ to $128.88^{\circ} \mathrm{C}$ (Figs. 1 and 2) indicated that physical complexation between pantoprazole sodium and rosin was through weaker ionic bonds.

\section{FTIR spectra}

Results from the FTIR spectra of drug: Rosin complex indicated that pantoprazole rosin complex retained most of the major peaks as seen in FTIR spectra of pure pantoprazole sodium (Figs. 3-5). Further confirming the possibility that physical complexation occurs between the pantoprazole sodium and rosin particle. FTIR spectra of optimized final formulation and pantoprazole rosin complex were found to be similar.

Physical stability testing of pantoprazole rosin complex in different pH (Fig. 6)

\section{$0.1 \mathrm{M}$ hydrochloric acid $\mathrm{pH} 1.2$}

Stability testing in $0.1 \mathrm{M}$ hydrochloric acid showed that it failed to stabilize the pantoprazole rosin complex and yellow color was obtained immediately after 5 minutes.

\section{Phosphate buffer $\mathrm{pH} 5$}

Solution changed to yellow color after 30 minutes when stability testing was performed in phosphate buffer $\mathrm{pH} 5$ (moderate acidic condition), it was found that the pantoprazole rosin complex was able to stabilize the drug to some extent.

\section{Phosphate buffer $p H 7.4$}

No color change was observed in phosphate buffer $\mathrm{pH} 6.8$ and pH 7.4 even after $90^{\text {th }}$ minute indicating the drug complex is stable in both the solution.

\section{Pre-compression parameters of blends F1-F10}

Angle of repose for different batches varies from $28.70^{\circ}$ to $32.30^{\circ}$ which indicates good to passable flow property. Compressibility index for all batches found to be $<12.81$, and Hausner ratio is $<1.15$ indicating good flow property and compressibility.

\section{Weight variation and friability test}

Weight variation test results varied from lowermost $199.54 \pm 0.42 \mathrm{mg}$ to maximum $200.83 \pm 0.92 \mathrm{mg}$ for batches F1-F10. Friability test values for all formulations were within the limits with maximum value of $0.25 \%$.

\section{Disintegration test}

All the formulations showed disintegration time within the limit for conventional tablets.

Assay

Drug content for all the batches was found to be within the limit as shown in Table 3.

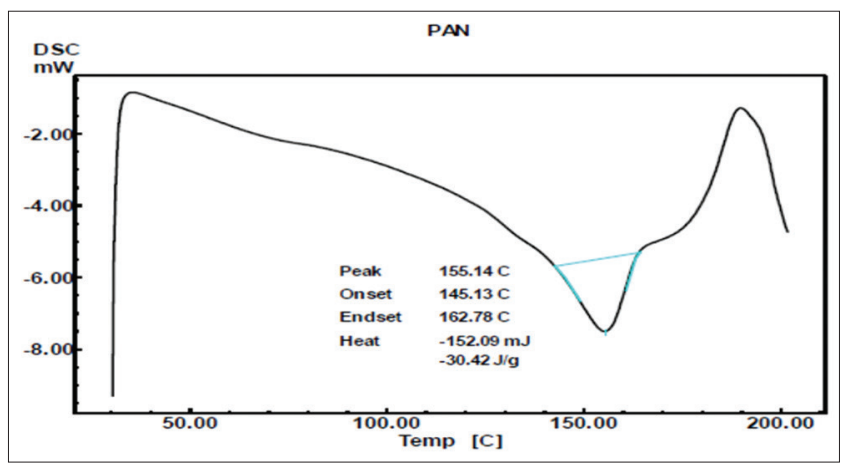

Fig. 1: Differential scanning calorimetry thermogram of pantoprazole sodium

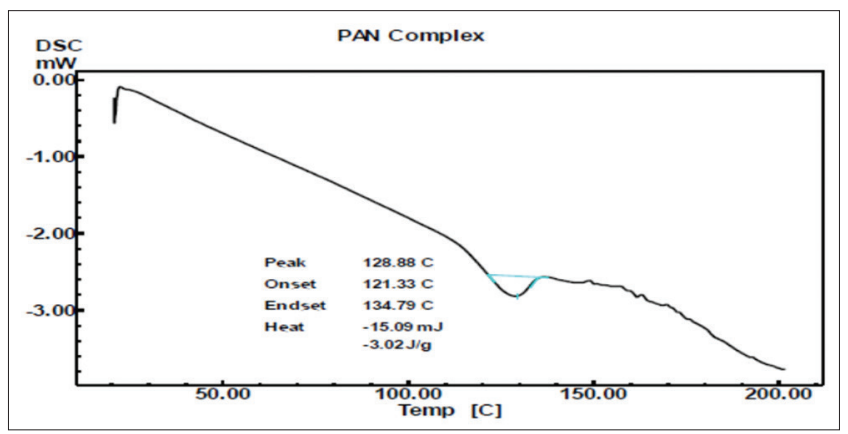

Fig. 2: Differential scanning calorimetry thermogram of pantoprazole rosin complex

In vitro dissolution study

Table 4 depicts the dissolution profiles of F1-F10 batches of pantoprazole rosin complex tablets.

Formulation batches F1-F5 were prepared using different diluents and $5 \%$ sodium starch glycolate as superdisintegrant. By interpreting the dissolution profile, compressibility property, and appearance, Avicel (F4 formulation) was selected as the suitable diluent for future batches of tablet. Batches F4, F6, and F7 had similar composition and only superdisintegrant varied. Formulations F6 and F7 had shown better drug release profile at $45^{\text {th }}$ minutes with $5 \%$ crospovidone and $5 \%$ croscarmellose sodium as superdisintegrant, respectively. Considering dissolution data of formulations F8-F10 with superdisintegrant $2.5 \%$ crospovidone, $2.5 \%$ croscarmellose, and $3.75 \%$ croscarmellose, respectively, it was observed that best release profile, i.e. $95 \%$ at the end of 30 minutes was obtained with $2.5 \%$ croscarmellose sodium (F9). Therefore, the released pantoprazolerosin ( $95 \%$ by 30 minutes) from $\mathrm{F} 9$ formulation will be stable at fed state of stomach as per stability study conducted at different $\mathrm{pH}$ 


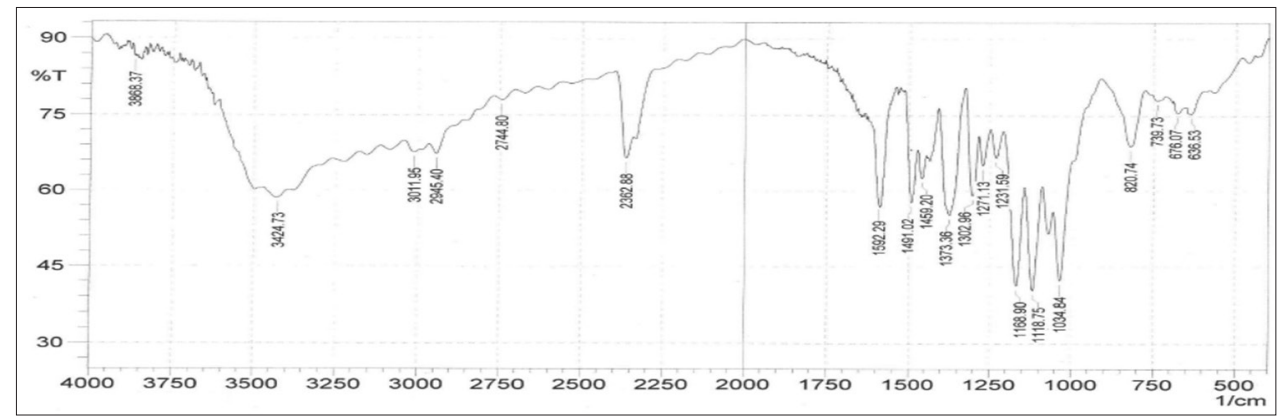

Fig. 3: Fourier transform infrared spectroscopy spectrum of pantoprazole sodium

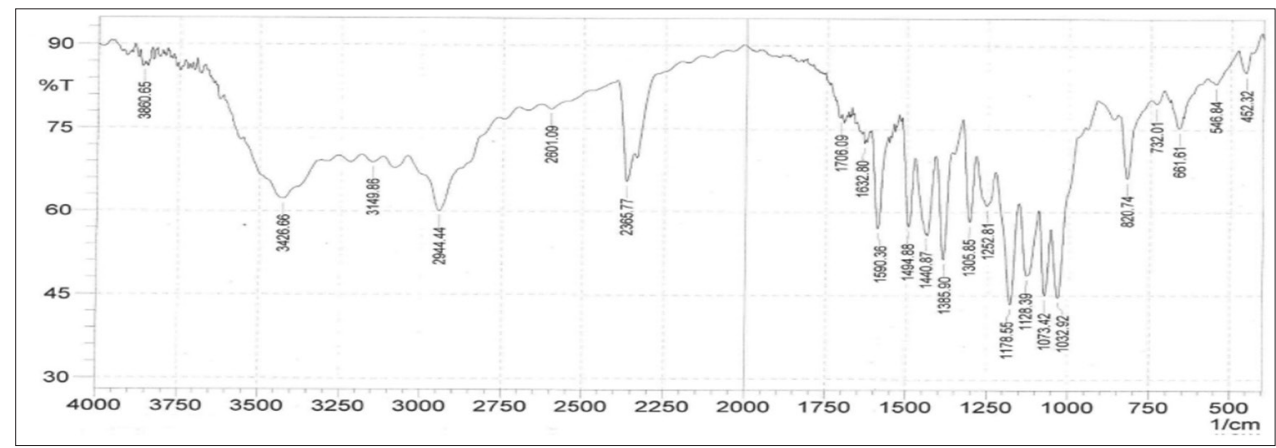

Fig. 4: Fourier transform infrared spectroscopy spectrum of pantoprazole rosin complex

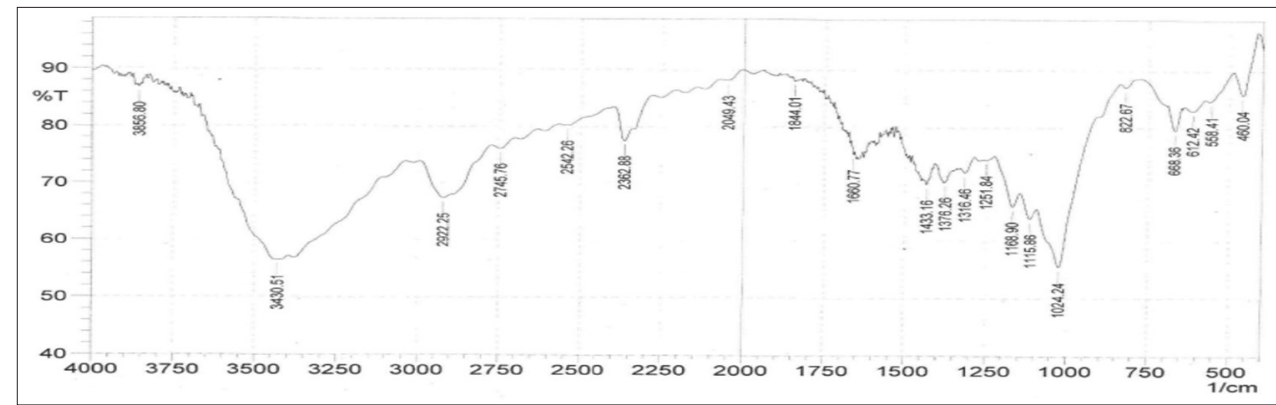

Fig. 5: Fourier transform infrared spectroscopy spectrum of optimized formulation F9

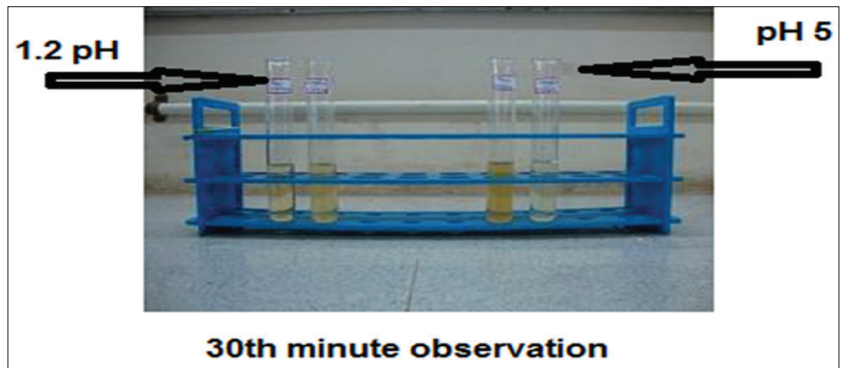

Fig. 6: Physical stability testing of pantoprazole rosin complex in $0.1 \mathrm{M}$ hydrochloric acid $\mathrm{pH} 1.2$ and in phosphate buffer $\mathrm{pH} 5$

values. Faster absorption might be observed due to increase in the lipophilicity of the complex.

\section{Stability studies on optimized tablets}

The result obtained were found to be similar to that of original preparation and shown to be stable as shown in Table 5. Hence, this formulation can be considered for future study.
Table 3: Assay of batches F1-F10

\begin{tabular}{ll}
\hline Batch & Assay* (mg of the drug/tablet) \\
\hline F1 & $19.82 \pm 1.36$ \\
F2 & $20.55 \pm 1.65$ \\
F3 & $19.15 \pm 0.58$ \\
F4 & $20.14 \pm 0.90$ \\
F5 & $18.65 \pm 0.80$ \\
F6 & $20.22 \pm 0.50$ \\
F7 & $19.56 \pm 0.30$ \\
F8 & $19.80 \pm 0.74$ \\
F9 & $19.88 \pm 0.35$ \\
F10 & $20.178 \pm 0.76$ \\
\hline
\end{tabular}

\section{CONCLUSION}

The present study demonstrated the successful preparation of pantoprazole-rosin complex and its direct compression into tablets. The methods adopted involved slow solvent evaporation and antisolvent addition for the preparation of pantoprazole rosin complex. If this process can be scaled up to manufacturing level, this technique has the potential to develop into an invaluable technology in future. 
Table 4: Dissolution profiles of pantoprazole rosin complex tablets: F1-F10

\begin{tabular}{|c|c|c|c|c|c|c|c|c|c|c|}
\hline \multirow{2}{*}{$\begin{array}{l}\text { Time } \\
\text { (minutes) }\end{array}$} & \multicolumn{10}{|c|}{ Average $\%$ cumulative drug dissolved $*$} \\
\hline & F1 & F2 & F3 & F4 & F5 & F6 & F7 & F8 & F9 & F10 \\
\hline 0 & $0 \pm 0.0$ & $0 \pm 0.0$ & $0 \pm 0.0$ & $0 \pm 0.0$ & $0 \pm 0.0$ & $0 \pm 0.0$ & $0 \pm 0.0$ & $0 \pm 0.0$ & $0 \pm 0.0$ & $0 \pm 0.0$ \\
\hline 10 & $61.80 \pm 5.70$ & $6.29 \pm 2.67$ & $57.63 \pm 3.25$ & $60.26 \pm 4.76$ & $69.69 \pm 3.47$ & $72.93 \pm 0.03$ & $80.09 \pm 3.10$ & $63.06 \pm 0.93$ & $84.86 \pm 3.85$ & $72.12 \pm 1.23$ \\
\hline 15 & $66.99 \pm 5.68$ & $6.24 \pm 0.20$ & $64.41 \pm 6.80$ & $73.17 \pm 8.51$ & $79.66 \pm 7.11$ & $85.48 \pm 0.75$ & $85.45 \pm 0.83$ & $76.08 \pm 2.32$ & $90.66 \pm 0.36$ & $86.06 \pm 1.75$ \\
\hline 30 & $76.36 \pm 5.43$ & $6.09 \pm 0.64$ & $70.07 \pm 1.75$ & $74.53 \pm 6.17$ & $78.81 \pm 1.60$ & $85.55 \pm 1.91$ & $85.24 \pm 2.59$ & $83.68 \pm 1.96$ & $95.42 \pm 1.04$ & $86.3 \pm 1.09$ \\
\hline 45 & $80.04 \pm 7.66$ & $7.40 \pm 4.34$ & $78.73 \pm 8.08$ & $82.87 \pm 9.47$ & $80.06 \pm 3.34$ & $90.27 \pm 3.57$ & $86.30 \pm 1.64$ & $85.18 \pm 2.53$ & $94.83 \pm 0.43$ & $88.65 \pm 3.67$ \\
\hline
\end{tabular}

Table 5: Dissolution profile and drug content of optimized formulation before and after stability study

\begin{tabular}{llll}
\hline Time (min) & \% CDR (initial) & \% CDR after one month & $\begin{array}{l}\text { Assay (initial) } \\
\text { (mg of drug/tablet) }\end{array}$ \\
\hline 0 & $0 \pm 0.0$ & $0 \pm 0.0$ & $\begin{array}{c}\text { Assay after one month } \\
\text { (mg of drug/tablet) }\end{array}$ \\
5 & $71.86 \pm 3.54$ & $71.95 \pm 3.55$ & $19.88 \pm 0.35$ \\
10 & $84.86 \pm 3.85$ & $85.31 \pm 4.01$ & \\
15 & $90.66 \pm 0.36$ & $90.71 \pm 0.54$ & \\
30 & $95.42 \pm 1.04$ & $94.91 \pm 0.46$ & \\
45 & $94.83 \pm 0.43$ & $95.95 \pm 0.18$ & \\
\hline
\end{tabular}

\section{REFERENCES}

1. Sawant K, Patel M, Patel J, Mundada P. Formulation, optimization, characterization and in vivo anti-ulcer activity of esomeprazole magnesium trihydrate gastroresistant microspheres. Int J Pharm Pharm Sci 2017;9(1):273.

2. Chakraborty S, Sarkar S, Debnath SK. Formulation development and evaluation of pantoprazole enteric coated tablets. Int J ChemTech Res 2009;1(3):663-6.

3. Tutuian R, Katz PO, Bochenek W, Castell DO. Dose-dependent control of intragastric $\mathrm{pH}$ by pantoprazole, 10,20 or $40 \mathrm{mg}$, in healthy volunteers. Aliment Pharmacol Ther 2002;16(4):829-36.

4. Shital KT, Sachin SG. Design and development of mucoadhesive buccal delivery for pantoprazole with stability enhancement in human saliva. Int J Pharm Pharm Sci 2013;5:122.

5. Anroop N, Rachna G, Rachna K, Shery J, Mahesh A. Formulation and evaluation of enteric coated tablets of proton pump inhibitor. J Basic Clin Pharm 2010;1(4):45-9.

6. Bozdag S, Çalis S, Sumnu M. Formulation and stability evaluation of enteric-coated omeprazole formulations. S.T.P Pharm Sci
1999;9(4):321-7

7. Chanchal M, Anil G, Mukesh S, Asha R. Pantoprazole and its enteric coating polymer concentration for stable coating in acid media in stomach. Int J Pharm Clin Res 2011;3(2):45-7.

8. Sumit C, Sibaji S, Sujit D. Formulation development and evaluation of pantoprazole enteric coated tablets. Int $\mathrm{J}$ ChemTech Res 2009;1(3):663-6

9. John NM. Formulation Development of Gliclazide Cocrystals: In vitro, Pharmacokinetic and Pharmacodynamic Evaluations [M Pharm Thesis]. Manipal: Manipal University; 2009.

10. Government of India, Ministry of Health and Family Welfare. Indian Pharmacopoeia. Vol. I. New Delhi: The Controller of Publication; 1996. p. 187-94.

11. Marques M. Dissolution media simulating fasted and fed states. Dissolution Technol 2004;11(2):p. 16.

12. ICH Harmonised Tripartite Guideline Stability Testing for New Dosage Forms Q1C; Dated 6, February; 2003. Available from: http://www.ich. org/fileadmin/Public_Web_Site/ICH_Products/Guidelines/Quality/ Q1C/Step4/Q1C_Guideline.pdf. [Last accessed on 2016 May 12]. 